\title{
Eğitim Fakültesi Öğrencileri İle Turizm Fakültesi Öğrencilerinin Mobil Öğrenmeye Yönelik Tutumları*
}

\section{Attitudes towards Mobile Learning of the Faculty of Education and the Faculty of Tourism Students}

\author{
Agâh Tuğrul KORUCU**if \\ Ertuğrul USTA* \\ Ahmet Naci ÇOKLAR
}

Received: 14 November 2016

Research Article

Accepted: 22 November 2018

\begin{abstract}
Mobile devices are an important representative of technological tools and the Internet development together. The importance of these devices which are called mobile due to their portability and which have shrunken hardware although their improved processing power is increasing in everyday life. The field of education is one of the areas where mobile devices are used. In this study, students' attitudes towards mobile technology in education have been investigated. In this context, 450 students from the faculties of education and tourism have been reached in 2014-2015 academic year. Students' attitudes towards mobile learning are analyzed in terms of different variables based on these two faculties, using Mobile Learning Attitude Scale. Research results indicated that the faculty of education students have more positive attitude towards mobile learning compared to the faculty of tourism students. According to the results, controlling faculty variable, although attitudes do not differentiate in terms of gender, grade level, graduated high school and the presence of Internet connection at households; attitudes towards mobile learning differentiate in terms of mobile device-computer possession.
\end{abstract}

Keywords: mobile learning, attitudes towards mobile learning, mobile educational technologies, distance education.

ÖZ: Mobil cihazlar, teknolojik araçların ve İnternetin birlikte gelişiminin önemli bir temsilcisi konumundadır. Artan işlem gücüne karşın donanımsal olarak küçülen ve taşınabilirliği nedeniyle mobil olarak adlandırılan bu cihazların hayatta her geçen gün önemi artmaktadır. Eğitim alanı da mobil cihazların kullanıldığı alanlardan biridir. Bu araştırmada da eğitim alanında mobil teknolojilere yönelik öğrenci tutumları araştırılmıştır. Bu kapsamda 2014-2015 eğitim öğretim yılında eğitim fakültesi ve turizm fakültesi öğrencilerinden toplam 450 öğrenciye ulaşılmıştır. Eğitim ve turizm fakültesi öğrencilerine demografik veri anketi ve "Mobil Öğrenmeye Yönelik Tutum Ölçeği” araştırma verilerini toplamak için uygulanmıştır. Bu iki fakülte temel alınarak ve "Mobil Öğrenmeye Yönelik Tutum Ölçeği" kullanılarak öğrencilerin mobil öğrenmeye yönelik tutumları farklı değişkenler açısından incelenmiştir. Araştırma sonucunda eğitim fakültesinde öğrenim gören öğrencilerin turizm fakültesinde öğrenim gören öğrencilere oranla daha fazla mobil öğrenmeye yönelik olumlu tutuma sahip oldukları, fakülte kontrol altında tutulmak kaydıyla cinsiyet, öğrenim görülen sınıf, mezun olunan lise türü ve kalınan yerde İnternete sahip olma durumlarına göre tutumlar farklılaşmazken kendine ait mobil cihaz/bilgisayar olma durumuna göre ise mobil öğrenmeye yönelik tutumun farklılaştığı sonucuna ulaşılmıştır.

Anahtar kelimeler: mobil öğrenme, mobil öğrenmeye yönelik tutum, mobil eğitim teknolojileri, uzaktan eğitim.

\footnotetext{
* This study has been presented orally at the $15^{\text {th }}$ International Classroom Teaching Education Symposium (USOS 2016).

${ }^{* *}$ Corresponding Author: Asst. Prof. Dr., Necmettin Erbakan University, Konya, Turkey, akorucu@erbakan.edu.tr

**** Prof. Dr., Necmettin Erbakan University, Konya, Turkey, ertugrulusta@gmail.com

***** Assoc. Prof. Dr., Necmettin Erbakan University, Konya, Turkey, ahmetcoklar@hotmail.com
}

\section{Citation Information}

Korucu, A. T., Usta, E., \& Coklar, A. N. (2019). Eğitim fakültesi öğrencileri ile turizm fakültesi öğrencilerinin mobil öğrenmeye yönelik tutumlari. Kuramsal Eğitimbilim Dergisi [Journal of Theoretical Educational Science], 12(1), 115. 


\section{Giriş}

Teknolojiye dayalı yaşanan gelişmeler doğrultusunda başta uzaktan eğitim olmak üzere eğitim alanının hemen hemen tümünde yeni kavramlar ve yaklaşımlar ortaya çıkmış ve bu kavramlar öğrenme süreciyle birlikte anılır hale gelmiştir. Mobil öğrenme bu kavramların başında gelmekte ve özellikle son 10 yılda internetin gelişip yaygınlaşması ile birlikte başta uzaktan eğitim olmak üzere öğrenme ve öğretme süreçlerinde yaygın ve etkili bir biçimde kullanılmaya başlanmıştır. Mobil öğrenme kavramının bu kadar hızlı ve kısa sürede yaygınlaşması internet destekli öğretim süreçlerinde de bu kavramın kullanımı sıklaştırmış ve mobil öğrenme (m-öğrenme) sıkça çalışılan bir alan olmuştur. Bu değişimin yaşanmasında mobil cihazların, masaüstü bilgisayarlarla kıyaslandığında kullanıcıya daha fazla zaman ve mekân özgürlüğü vermesi ve daha ucuz olmaları açısından oldukça avantajlı olmalarından kaynaklandığı söylenebilir (Oran \& Karadeniz, 2007). Alan yazında son yıllarda yapılan araştırmalarda da vurgulandığı üzere, yeni binyılın öğrencilerinin önemli bir bölümünün mobil uygulamaları çalıştırabilecek akıllı telefonlara ve tabletlere sahip olduklarını göstermektedir (Korkmaz, 2015).

Bireylerin sürekli hareket halinde olabilmesinin öğrenme için dezavantaj değil avantaj olarak görülmesi ve benimsenmesi mobil öğrenmenin diğer yaklaşımlardan en önemli farkı olarak görülmektedir (Chang, Chen, \& Hsu, 2011; Cochrane, 2010; Sharples, Taylor, Vavoula ve diğerleri, 2005). Nitekim yapılan tanımlamalar da bu eksendedir. Quinn (2000) mobil öğrenmeyi avuç içi cihazların öğrenme için kullanılması şeklinde ifade etmiştir. Bir mobil öğrenme, öğrenmenin önemli bir kısmının okul dışında, insanların, aktivitelerini eğitimsel süreç ve sonuçları mümkün kılacak şekilde yapılandırmasıyla gerçekleştiği durumları kapsamalıdır (Çakır, 2011). Mobil teknolojilerin kolay ulaşılabilirlik ve taşınabilirlik niteliği sayesinde özellikle eğitim alanındaki alıştırma ve uygulama gibi öğrenme etkinlikleri sınıf ortamının dişına da taşınabilmektedir (Saran, Seferoğlu, \& Çağıltay, 2009). Cep telefonları ve giderek kullanımı yaygınlaşan tablet bilgisayarlardan eğitim kurumlarının da desteğiyle öğrenme-öğretme süreçlerinde faydalanmanın mümkün olduğu birçok araştırmada vurgulanmaktadır. (Corlett, Sharples, Bull, \& Chan, 2005; Ozan, 2013; Reychav \& Wu, 2014). Bu araştırmalardan ortaya çıkan sonuç öğrencilerin öğrenme etkinliklerinin mobil cihazlarla desteklenmesinin önemli katkılar sağlayabileceği, eğitim açısından bu teknolojilerin önemli potansiyellere sahip olduğu ve bu alana yatırım yapılmasının gelecek açısından önemli olabileceğini göstermektedir. Buna ek olarak, mobil öğrenmenin öğrenciler arasındaki etkileşimi artırmanın yanında, sınıf içi işbirlikçi öğrenme süreçlerine de destek olabileceği gibi önemli sonuçlar ürettiği vurgulanmaktadır (Gay, Stefanone, Grace-Martin, \& Hembrooke, 2001).

Mobil Öğrenmeye ilişkin yukarıda vurgulanan birçok avantajın ve başarılı çalışmanın yanında birtakım belirsizliklerin de olduğu söylenebilir. Bu bağlamda, farklı fakültelerin farklı sınıflarında öğrenim gören üniversite öğrencilerinin mobil öğrenmeye ilişkin görüşlerini ve tutumlarını incelemek, bir başka ifadeyle öğrencileri analiz etmek daha sonraki öğrenme süreçlerinde mobil uygulamaya yönelik tasarımların daha etkili bir biçimde tasarlanmasını mümkün kılabilecektir. Bu temel sayıltıdan hareketle bu araştırmanın amacı; eğitim ve turizm fakültelerinde öğrenim gören öğrencilerin mobil 
öğrenmeye ilişkin tutum ve görüşlerini farklı değişkenler açısından incelemek olarak belirlenmiştir. Bu kapsamda aşağıdaki sorulara yanıtlar aranmıştır.

1. Turizm ve Eğitim Fakültesi öğrencilerinin mobil öğrenmeye yönelik tutumları farklılaşmakta mıdır?

2. Öğrencilerin Turizm ve Eğitim Fakültesi öğrencileri olmaları kontrol altında tutulmak kaydıyla mobil öğrenmeye yönelik tutumları cinsiyet, mezun olunan lise türü, öğrenim görülen sınıf, mobil cihaz veya bilgisayara sahip olma ve kalınan yerde İnternete sahip olma değişkenlerine göre farklılaşmakta mıdır?

\section{Yöntem}

\section{Araştırmanın Modeli}

Çalışmada nicel araştırma yöntemi benimsenmiş olup, tarama modeli kullanılmıştır. Geçmişte ya da o anda var olan bir durumu var olduğu şekliyle betimlemeyen, tanımlamayı amaçlayan araştırma yaklaşımıdır. Araştırmaya konu olan her neyse onları değiştirme ve etkileme çabası yoktur bu modelde sonuç ortadadır. Amaç o şeyi doğru bir şekilde gözlemleyip belirleyebilmektir. Asıl amaç değiştirmeye kalkmadan gözlemektir. (Karasar, 1999) Tarama modelinde bilimin gözleme kaydetme, olaylar arasındaki ilişkileri tespit etme, kontrol edilen değişmez ilişkiler üzerinde genellemelere varma vardır. Yani bilimin tasvir fonksiyonu ön plandadır (Yıldırım \& Şimşek, 2008). Bu kapsamda Turizm ve Eğitim Fakültesi öğrencilerinin mobil öğrenmeye yönelik görüşleri ölçek yardımı ile toplanarak mevcut durum ortaya konmaya çalışılmıştır.

\section{Evren ve Örneklem}

Araştırmanın evrenini 2014-2015 yılı güz döneminde Konya il Merkezinde yer alan Selçuk ve Necmettin Erbakan Üniversitelerindeki Turizm ve Eğitim Fakültesi öğrencileri oluşturmaktadır. Bu kapsamda her iki üniversitede ilgili dönemde öğrencileri olan Selçuk Üniversitesi Turizm Fakültesinde okuyan 200 öğrenci (TFÖ) ile Necmettin Erbakan Üniversitesi Ahmet Keleşoğlu Eğitim Fakültesinde okuyan 250 öğrenciye (EFÖ) basit rastsal örnekleme yöntemi ile seçilmiş ve araştırma çalışma grubunu oluşturmuştur. Araştırma örneklemine ait tanımlayıcı istatistik sonuçları şu şekildedir; 
Tablo 1

Araştırma Çalışma Grubuna Ait Tanımlayıcı İstatistikler

\begin{tabular}{lcccc}
\hline & & $\begin{array}{c}\text { Eğitim Fak. } \\
\text { (EFÖ) }\end{array}$ & $\begin{array}{c}\text { Turizm Fak. } \\
\text { (TFÖ) }\end{array}$ & Toplam \\
\hline Cinsiyet & Erkek & 126 & 108 & 234 \\
& Kadın & 124 & 92 & 216 \\
\hline \multirow{2}{*}{ Mezun Olunan } & Normal Lise & 61 & 41 & 102 \\
Lise Türü & Anadolu Lisesi & 63 & 35 & 98 \\
& Süper Lise & 6 & 47 & 53 \\
& Ticaret Lisesi & 12 & 48 & 60 \\
& Mes.ve Tek. Lis. & 102 & 27 & 129 \\
& Açıköğrt. Lisesi & 6 & 2 & 8 \\
\hline \multirow{3}{*}{ Sinıf } & 1. sınıf & 0 & 48 & 150 \\
& 2. sınıf & 53 & 97 & 210 \\
& 3. sınıf & 155 & 55 & 42 \\
\hline Kendine Ait & 4. sınıf & 42 & 0 & 350 \\
Bilg./Mobil Cihaz & Var & 250 & 100 & 100 \\
\hline Kalınan Yerde & Yok & 0 & 100 & 277 \\
İnternet Sahipliği & Var & 212 & 65 & 162 \\
\hline & Yok & 38 & 124 & \\
\hline
\end{tabular}

Tablo 1 incelendiğinde katılımcıların cinsiyeti açısından, eğitim fakültelerinde kadın ve erkek öğrenci sayılarının birbirine yakın, turizm fakültesinde ise erkeklerin kadınlardan biraz daha fazla olduğu söylenebilir. Ayrıca lise türü açısından normal lise her iki grupta da benzer bir orana sahipken, Eğitim Fakültesinde meslek ve teknik liselerin, Turizm Fakültesinde ise ticaret lisesinin daha fazla orana sahip olması dikkat çekicidir. Sınıf açısından Eğitim Fakültesinde birinci sınıflar, Turizm Fakültesinde dördüncü sınıf öğrencisi temsil edilememiştir. Mobil cihazların veya bilgisayarların sahipliği açısından Eğitim Fakültesi öğrencilerinin tamamı mobil cihaza veya bir bilgisayara sahip olduklarını ifade ederken, Turizm Fakültesinde öğrencilerin yarısında cep telefonu, tablet ya da bilgisayar bulunmamaktadır.

\section{Veri Toplama Araci}

Eğitim ve Turizm Fakültesi öğrencilerine araştırmacıların araştırma alt amaçları doğrultusunda geliştirdiği demografik veri anketi ve Çelik'in (2013) geliştirmiş olduğu "Mobil Öğrenmeye Yönelik Tutum Ölçeği” veri toplamak için uygulanmıştır. Ölçekteki maddeler 5'li likert tip olarak geliştirilmiştir. Çelik (2013) tarafından ölçeğin yap1 geçerliğini test etmek amaciyla yapılan faktör analizleri sonucunda 21 ölçek maddesinin 4 faktörde toplandığı ve ölçeğin toplam varyansın \%51.116'sını açıkladığı ve güvenirlik için hesaplanan Cronbach Alpha değerinin .881 olduğu ifade edilmiştir. 


\section{Verilerin Analizi}

Öğrencilerden elde edilen veriler bilgisayarlı istatistik paket programı olan SPSS 22 paket programına girilerek değerlendirilmiştir. Genel mobil teknolojilerine yönelik durumlarını değerlendirilmesi, bitirdikleri lise türü, sınıfı, kaldığınız yerde kendinize ait bilgisayarınız veya mobil cihaz var mı?, kaldığınız yerde kendinize ait İnternet var mı? değişkenlerine göre mobile teknolojilere yönelik tutumları arasında anlamlı bir fark olup olmadığını belirlemek için bağımsız örneklemler için t testi ve kovaryans analizi (ANCOVA) yapılmıştır. Araştırmada yapılan tüm istatistiksel analizlerde anlamlılık düzeyi .05 olarak kabul edilmiştir.

\section{Bulgular}

Öğrencilerin Mobil Öğrenmeye yönelik tutumları geneli ve alt amaçlarda belirtilen değişkenler açısından incelenmiş elde edilen bulgular başlıklar şeklinde verilmiştir.

\section{Fakülte Türüne Göre Öğrencilerin Mobil Öğrenmeye Yönelik Tutumları}

Eğitim Fakültesi Öğrencileri (EFÖ) ile Turizm Fakültesi Öğrencilerinin (TFÖ) Mobil Teknolojilere Yönelik Tutum Ölçeğine (MTYTÖ) vermiş oldukları cevapların karşılaştırma sonuçları Tablo 2'de verilmiştir.

Tablo 2

EFÖ ve TFÖ Mobil Teknolojilere Yönelik Tutum Ölçeği Puanları

\begin{tabular}{cccccccc}
\hline & Gruplar & $n$ & $\overline{\mathrm{X}}$ & $\mathrm{S}$ & $s d$ & $\mathrm{t}$ & $\mathrm{p}$ \\
\hline \multirow{2}{*}{ MTYTÖ } & EFÖ & 250 & 71.31 & 8.03 & 448 & 12.19 & $.001 *$ \\
& TFÖ & 200 & 57.63 & 15.30 & & & \\
\hline
\end{tabular}

Eğitim Fakültesi öğrencileri (EFÖ) ile Turizm Fakültesi öğrencilerinin (TFÖ) Mobil Teknolojilere Yönelik Tutum Ölçeğine (MTYTÖ) vermiş oldukları cevapların karşılaştırmaları sonucunda iki grup arasında farklılığın olduğu Tablo 2'den görülebilir Her iki gruba uygulanan MTYTÖ ölçeği sonucunda (EFÖ ortalaması $\bar{x}=71.31$; TFÖ ortalaması $\bar{x}=57.63$ ) EFÖ'nin TFÖ puanlarından daha yüksek olduğu belirlenmiştir (Tablo 2). Bu sonuç EFÖ öğrencilerinin TFÖ öğrencilerine göre mobile öğrenmeye yönelik tutumlarının daha yüksek olduğunu göstermektedir.

\section{Cinsiyet ve Fakülte Türü Değişkenleri Açısından Öğrencilerin Mobil Öğrenmeye Yönelik Tutumları}

Öncelikli olarak öğrencilerin cinsiyetlerine göre mobil öğrenmeye yönelik düzeltilmiş tutum puanları incelenmiştir. Buna göre öncelikli olarak erkek öğrencilerin ve $(\overline{\mathrm{x}}=65.67$; ss=13.743) ile kadın öğrencilerin $(\overline{\mathrm{x}}=64.75$; ss=13.538) mobil öğrenmeye yönelik düzeltilmiş tutum puanları hesaplanmıştır. Cinsiyete ve fakülte türüne göre hesaplanan ANCOVA sonuçları ise Tablo 3 'te verilmiştir. 
Tablo 3

MTYTÖ Ölçeğine Göre Düzeltilmiş Puanların Cinsiyet Değişkeni Puanlarının Fakülte Türüne Göre ANCOVA Sonuçları

\begin{tabular}{lccccc}
\hline Varyansın kaynăgı & Kareler toplamı & $s d$ & $\begin{array}{c}\text { Kareler } \\
\text { ortalaması }\end{array}$ & $F$ & $p$ \\
\hline Cinsiyet & 3.152 & 1 & 3.152 & .023 & .881 \\
Fakülte Türü & 20988.855 & 1 & 20988.855 & 149.939 & .000 \\
$\begin{array}{l}\text { Cinsiyet * Fakülte } \\
\text { Türü } \\
\text { Hata }\end{array}$ & 49.253 & 1 & 49.253 & .352 & .553 \\
\hline Toplam & 62432.454 & 446 & 139.983 & & \\
\hline
\end{tabular}

Tablo 3'teki ANCOVA sonuçlarına göre farklı okullarda eğitim gören EFÖ ve TFÖ’nin cinsiyetlerine göre MTYTÖ ölçeğinden almış oldukları ortalama puanları arasında anlamlı bir farkın olmadığ 1 bulgusuna ulaşılmıştır, $\mathrm{F}(1,1)=49.253, p>0.05$, $p=.553$. Bir başka deyişle EFÖ ve TFÖ öğrencilerinin mobil teknolojilere yönelik tutumları arasındaki var olan fark cinsiyetleri ile ilişkili değildir.

\section{Mezun Olunan Lise Türü ve Fakülte Türü Değişkenleri Açısından Öğrencilerin Mobil Öğrenmeye Yönelik Tutumları}

Öğrencilerin mezun olduğu lise türünün de mobil öğrenmeye yönelik tutumlarını değiştirebilecek önemli bir değişken olduğu düşüncesi ile bu değişkene göre öğrencilerin düzeltilmiş mobil öğrenme tutum puanları hesaplanmıştır. Buna göre Normal Lise ( $\bar{x}=68.09 ; s s=12.582)$, Anadolu lisesi ( $\bar{x}=65.43 ; s s=11.816)$, Süper lise $(\overline{\mathrm{x}}=59.05 ; \quad$ ss=14.792), Ticaret lisesi $(\overline{\mathrm{x}}=59.33 ; \quad$ ss=17.301 $)$, Meslek-Teknik lise $(\overline{\mathrm{x}}=67.87 ;$ ss=11.954), Açık öğretim lisesi ( $\overline{\mathrm{x}}=68.75 ;$ ss=9.982), düzeltilmiş mobil öğrenme puanları incelenmiş ve fakülte türü-mezun olunan lise türü değişkenine göre ANCOVA sonuçları incelenmiştir (Tablo 4).

Tablo 4

MTYTÖ Ölçeğine Göre Düzeltilmiş Puanların Mezun Oldukları Lise Türü Değişkeni Puanlarının Fakülte Türüne Göre ANCOVA Sonuçları

\begin{tabular}{lccccc}
\hline Varyansın kaynağı & Kareler toplamı & $s d$ & $\begin{array}{c}\text { Kareler } \\
\text { ortalaması }\end{array}$ & $F$ & $p$ \\
\hline Fakülte Türü & 5656.225 & 1 & 5656.225 & 40.242 & .000 \\
Lise turu & 395.502 & 5 & 79.100 & .563 & .729 \\
Lise turu * Fakülte Türü & 398.923 & 5 & 79.785 & .568 & .725 \\
Hata & 61563.295 & 438 & 140.555 & & \\
\hline Toplam & 1998441.000 & 450 & & & \\
\hline
\end{tabular}


Tablo 4'teki ANCOVA sonuçlarına göre farklı okullarda eğitim gören EFÖ ve TFÖ’nin mezun oldukları lise türlerine göre MTYTÖ ölçeğinden almış oldukları ortalama puanları arasında anlamlı bir farkın olmadığı bulgusuna ulaşılmıştır, $\mathrm{F}(1,5)=79.795, p>0.05, p=.725$. Bir başka deyişle EFÖ ve TFÖ öğrencilerinin mobil teknolojilere yönelik tutumları arasındaki var olan fark mezun oldukları lise türleri ile ilişkili değildir.

\section{Öğrenim Görülen Sınıf ve Fakülte Türü Değişkenleri Açısından Öğrencilerin Mobil Öğrenmeye Yönelik Tutumları}

Öğrenim görülen sınıf bir başka ifade ile üniversite içerisinde olası deneyimleri düşünülerek öğrencilerin öğrenim gördükleri sınıflara göre mobil öğrenmeye yönelik tutumları araştırılmıştır. Buna göre öğrencilerin mobil öğrenmeye yönelik tutumları sınıf değişkenine göre 1.sınıflar için ( $\bar{x}=58.12 ; \mathrm{ss}=15.694), 2$.sınıf $(\bar{x}=62.52 ; \mathrm{ss}=14.452)$, 3. sınıf $(\overline{\mathrm{x}}=67.18 ; \mathrm{ss}=12.147)$ ve 4. sinıflar için $(\overline{\mathrm{x}}=73.28 ;$ ss=8.454) olarak hesaplanmıştır. Değerler incelendiğinde 4. sınıfa doğru ilerledikçe mobil öğrenmeye yönelik düzeltilmiş tutum puanlarının arttığı buna karşın standart sapmalarının azaldı̆̆ görülebilir. Öğrencilerin genelinde bir deneyim kazanıldığı ve grup olarak bir artışın olduğu söylenebilir. Bu farklılığın fakülte değişkeni kontrol altında tutularak sınıflara göre değişikliğini incelemek için yapılan ANCOVA testi sonuçları Tablo 5'te verilmiştir.

Tablo 5

MTYTÖ Ölçeğine Göre Düzeltilmiş Puanların Öğrenim Gördükleri Sınıf Değişkeni Puanlarının Fakülte Türüne Göre ANCOVA Sonuçları

\begin{tabular}{lccccc}
\hline Varyansın kaynağı & Kareler toplamı & $s d$ & $\begin{array}{c}\text { Kareler } \\
\text { ortalaması }\end{array}$ & $F$ & $p$ \\
\hline Fakülte Türü & 14364.602 & 1 & 14364.602 & 102.959 & .000 \\
Sinıf & 542.063 & 3 & 542.063 & 3.885 & .049 \\
Sınıf * Fakülte Türü & 519.988 & 3 & 519988 & 3.727 & .054 \\
Hata & 61945.726 & 444 & 139.517 & & \\
\hline Toplam & 1998441.000 & 450 & & & \\
\hline
\end{tabular}

Tablo 5'teki ANCOVA sonuçlarına göre farklı okullarda eğitim gören EFÖ ve TFÖ’nin öğrenim gördükleri sınıf türlerine göre MTYTÖ ölçeğinden almış oldukları ortalama puanları arasında anlamlı bir farkın olmadığı bulgusuna ulaşılmıştır, $\mathrm{F}(1,3)=519.98, p>0.05, p=.054$. Bir başka deyişle EFÖ ve TFÖ öğrencilerinin mobil teknolojilere yönelik tutumları arasındaki var olan fark öğrenim gördükleri sınıf türleri ile ilişkili değildir.

\section{Mobil Cihaz/Bilgisayara Sahip Olma Durumu ve Fakülte Türü Değişkenleri Açısından Öğrencilerin Mobil Öğrenmeye Yönelik Tutumları}

Öğrencilerin mobil cihazlara sahip olma durumu onların deneyimlerini artıracağ düşüncesi ile kendilerine ait bir mobil cihaz olma durumuna göre öğrencilerin mobil öğrenme tutum puanları da incelenmiştir. Buna göre öğrencilerin mobil teknolojilere veya bilgisayar sahip olanların mobil öğrenmeye yönelik tutumları $(\overline{\mathrm{x}}=67.85$; 
ss=12.208) ile sahip olmayanların puanları ( $\bar{x}=56.05 ; \mathrm{ss}=14.445)$ farklılaşmaktadır. Tablo 6'da ise öğrencilerin fakülte değişkeni kontrol altında tutulmak üzere bilgisayar ve mobil cihaz sahipliğinin mobil öğrenmeye yönelik tutumları üzerindeki ANCOVA sonuçları verilmiştir.

Tablo 6

MTYTÖ Ölçeğine Göre Düzeltilmiş Puanların Kendine Ait Mobil Cihaz/Bilgisayar Olma Durumu Değişkeni Puanlarının Fakülte Türüne Göre ANCOVA Sonuçları

\begin{tabular}{lccccc}
\hline Varyansın kaynağı & $\begin{array}{c}\text { Kareler } \\
\text { toplamı }\end{array}$ & $s d$ & $\begin{array}{c}\text { Kareler } \\
\text { ortalaması }\end{array}$ & $F$ & $p$ \\
\hline Fakülte Türü & 10468.231 & 1 & 10468.231 & 75.223 & .000 \\
Kendi bilgisayar & .000 & 0 &. &. &. \\
Kendi bilgisayar * Fakülte Türü & .000 & 0 &. &. \\
Hata & 62205.376 & 447 & 139.162 & \\
\hline Toplam & 1998441.00 & 450 & & \\
\hline
\end{tabular}

Tablo 6'daki ANCOVA sonuçlarına göre farklı okullarda eğitim gören EFÖ ve TFÖ'nin kendine ait mobil cihaz/bilgisayara sahip olma durumuna göre MTYTÖ ölçeğinden almış oldukları ortalama puanları arasında anlamlı bir farkın olduğu bulgusuna ulaşılmıştır, $\mathrm{F}(1,0)=139.16, p<0.05, p=.000$. Bir başka deyişle EFÖ ve TFÖ öğrencilerinin mobil teknolojilere yönelik tutumları arasındaki var olan fark kendine ait mobil cihaza sahip olma durumu ile ilişkilidir. Kendine ait mobil cihaza sahip olanların mobile teknolojilere yönelik tutumları $(\overline{\mathrm{x}}=67.85)$ sahip olmayanlara $(\overline{\mathrm{x}}=56.05)$ göre anlamlı oranda yüksek çıkmıştır.

Son olarak kalınan yerde İnternet olma durumunun mobil öğrenmeyi artıracağ düşüncesi ile kalınan yere göre mobil öğrenmeye yönelik tutum puanları incelenmiştir. Buna göre kaldığı yerde İnterneti olan öğrencilerin mobil öğrenmeye yönelik tutum puanları ( $\overline{\mathrm{x}}=67.61$; ss=12.382) ile olmayanların puanları $(\overline{\mathrm{x}}=61.308 ; \mathrm{ss}=14.650)$ farklılık göstermektedir. Ancak fakülte türüne göre farklılığın anlamlılığını belirlemek için ANCOVA yapılmış ve sonuçlar Tablo 7'de verilmiştir.

Tablo 7

MTYTÖ Ölçeğine Göre Düzeltilmiş Puanlarin Kalınan Yerde Internete Sahip Olma Durumu Değişkeni Puanlarinin Fakülte Türüne Göre ANCOVA Sonuçları

\begin{tabular}{lccccc}
\hline Varyansın kaynağı & $\begin{array}{c}\text { Kareler } \\
\text { toplamı }\end{array}$ & $s d$ & $\begin{array}{c}\text { Kareler } \\
\text { ortalaması }\end{array}$ & $F$ & $p$ \\
\hline Fakülte Türü & 15764.833 & 1 & 15764.833 & 113.385 & .000 \\
Kendi İnterneti olma & .257 & 1 & .257 & .002 & .966 \\
Kendi İnternet * Fakülte Türü & 16.883 & 1 & 16.883 & .121 & .728 \\
Hata & 61871.972 & 445 & 139.038 & & \\
\hline Toplam & 1998441.00 & 450 & & & \\
\hline
\end{tabular}


Tablo 7'deki ANCOVA sonuçlarına göre farklı fakültelerde eğitim gören EFÖ ve TFÖ’nin kendine ait İnternete sahip olma durumlarına göre MTYTÖ ölçeğinden almış oldukları ortalama puanları arasında anlamlı bir farkın olmadığı bulgusuna ulaş1lmıştır, $\mathrm{F}(1,1)=16.883, p>0.05, p=.728$. Bir başka deyişle EFÖ ve TFÖ öğrencilerinin mobil teknolojilere yönelik tutumları arasındaki var olan fark kendine ait İnternete sahip olma durumları ile ilişkili değildir.

\section{Sonuç ve Tartışma}

Zaman ve mekâna bağlı olmaksızın bilgiye ulaşabilme imkânı sağlayan teknolojik gelişmelerle birlikte öğrenme uygulamaları da değişmektedir. Özellikle İnternetin gelişimine paralel olarak teknolojik cihazlarda işlem kapasitesi adına gelişmiş buna karşın donanımsal anlamda küçülmüştür. Günümüzde mobil teknolojiler hem ucuzlayarak erişim firsatını artırmakta, hem de uzaktan eğitim fırsatlarını bireylere sunabilmektedir (Oran \& Karadeniz, 2007). Bu nedenle formal veya informal anlamda eğitim amaçlı mobil teknolojilerin yaygın olarak kullanıldığı ve gelecekte daha çok yer edineceği söylenmektedir (Bannan, Cook, \& Pachler, 2016; Corlett,ve diğerleri, 2005; Sharples, Taylor, \& Vavoula, 2005).

Uzaktan eğitim aracı olarak mobil öğrenmeyi formal anlamda tercih eden kurumlar arasında üniversitelerin öncelikli olduğu, bunda ise özellikle bu gruptaki öğrencilerin teknoloji kullanım yeterliklerinin, erişim fırsatlarının, eğitim şartlarının/zorunluluklarının önemli söylenebilir. Bu açıdan üniversite öğrencilerinin mobil öğrenmeye yönelik tutumları iki farklı fakülte (Turizm Fakültesi ve Eğitim Fakültesi) öğrencileri dikkate alınarak ve kontrol değişkeni olarak kullanılarak araştırılmıştır. Çelik (2013) tarafından geliştirilen ölçek ile toplam 450 öğrenciden toplanan verilerden aşağıdaki sonuçlar elde edilmiştir.

Eğitim Fakültesi ve Turizm Fakültesi öğrencilerinin mobil öğrenmeye yönelik tutumları farklılık göstermektedir. Eğitim Fakültesi öğrencileri Turizm Fakültesi ögrencilerine oranla daha fazla olumlu tutuma sahiptirler. Akbıyık ve Kantaroğlu (2017) işletme fakültesi ile eğitim fakültesi öğrencileri arasında yaptığı araştırmada, her iki fakülte öğrencilerinin mobil öğrenmeye yönelik tutumlarının genel olarak farklılaşmadığını, ancak gerek bölümlere göre gerek tutumu oluşturan alt boyutlara göre farklılığın bulunduğunu belirtmiştir. Mobil öğrenmeye yönelik tutumlar arasındaki farklılık Usluel ve Mazman (2010) tarafından ifade edilen teknolojinin kabullenmesine yönelik model ile açıklanabilir. Usluel ve Mazman (2010) teknolojinin kabulünde yarar algısı, kolaylaştırıcı faktörler, sosyal etkiyi önemli faktörler olarak sıralarken, en önemli faktör olarak yarar algısını ifade etmektedir. Bu açıdan iki fakültedeki gerek yarar algısı, gerek kolaylaştırıcı faktörler, gerek sosyal etki tutumları etkilemiş olabilir. Lau ve Woods (2008) ise sunulan imkân ve ortamın da etkisi olduğunu ifade ederken, Bannan, Cook ve Pachler (2016) ise mobil öğrenmeye yönelik deneyimlerin önemli olduğunu ifade etmiştir. $\mathrm{Bu}$ açıdan fakülteler arasındaki teknoloji kullanımına yönelik algı, deneyim ve sosyal etkinin farklılaşması mobil öğrenmeye yönelik tutumlardaki farklılığı da etkilemiş olabilir.

Diğer yandan fakülte değişkeni kontrol altında tutulmak şartıyla cinsiyet, bulunduğu sınıf, mezun olunan lise türü ve kalınan yerde İnternete sahip olma durumuna göre mobil öğrenmeye yönelik tutumlarda değişiklik olmadığı sonucuna ulaşılmıştır. Kıcı (2010) tarafından mobil öğrenmenin üniversitedeki öğrenciler 
üzerindeki beklentileri araştırılmış ve araştırmaya benzer şekilde öğrencilerin beklentilerinin cinsiyet, mezun olunan lise türü ve sınıf değişkenine göre farklılaşmadığ 1 sonucu bulunmuştur. Kukulska-Hulme ve Traxler (2007) mobil öğrenmenin henüz yeni gelişmekte olduğunu ve eğitimde uygulamaların gerekliliğini belirtmiştir. Bu açıdan ögrencilerde mobil teknolojilere yönelik tutum oluşturacak formal eğitimlerin yeterince yer bulmaması bu sonuçların farklılığın engellemiş olabilir.

Buna karşın mobil cihazlara/bilgisayarlara sahip olma açısından öğrencilerin mobil öğrenmeye yönelik tutumları farklılık göstermektedir. Jones (2002) çevrimiçi öğrenme ortamlarında kendine ait bilgisayar, kablosuz bağlantı sahibi olanların \%80'inin öğrenme deneyimlerinin daha fazla arttığını ifade etmiştir. Bu açıdan Jones ve diğerleri (2009) üniversite öğrencilerinin bilgisayar ve İnternet sahipliğinin artırılmasını önermişlerdir. Diğer yandan Usluel ve Mazman (2010) da teknoloji entegrasyonunda teknoloji erişim firsatlarının önemini vurgulamaktadır. Bu açıdan mobil öğrenme ortamlarına sahip olmanın mobil öğrenmeye yönelik tutumları etkilemesinin doğal olduğu da söylenebilir.

Araştırma kapsamında elde edilen sonuçlar dikkate alındığında araştırmada araştırmanın farklı fakülteleri kapsayacak şekilde yeniden desenlenmesi önerilebilir. Araştırmada fakültelere göre eğitim fakültesi ile turizm fakültesi öğrencileri arasında mobil öğrenmeye yönelik tutumun farklılaştığı görülmüştür. Bunun nedenlerini ortaya koyacak nitel araştırmaların desenlemesi önerilebilir. 


\section{Summary}

Purpose and Significance: Learning is at the top of mobile learning concepts, and especially in the last 10 years due to development and widespread use of Internet infrastructure, it has become widely used in learning teaching progress, particularly in distance education. Considering and adopting learning as an advantage rather than a disadvantage for individuals' constant motion is considered the most important difference of mobile learning from other approaches (Chang, Chen, \& Hsu, 2011; Cochrane, 2010; Sharples, Taylor, Vavoula et al., 2005).

The result of research revealed that supporting learning activities of students with mobile devices can provide an important contribution; these technologies have significant potential in terms of education and the investment in this area can be important for the future. In addition, the result of research emphasized that mobile learning improves interaction between students and supports collaborative learning in the classroom (Gay, Grace-Martin, \& Hembrook, 2001).

Besides many advantages and successful work highlighted above in mobile learning; it can be stated that there are some uncertainties. In this context, examining and analyzing university students' views and attitudes towards mobile learning who study in different classes in different faculties, allow us to effectively plan mobile application designs for further learning processes. From this basic assumption, the aim of this study is determined as examining attitudes and aspects of students who study in the faculty of education and faculty of tourism towards mobile learning in terms of different variables.

Methods: In this research, the quantitative research methodology is adopted and survey method is used. This is a research approach which aims to describe and identify a situation happened in the past or exists at the moment as it is. There is no effort to change and effect whatever the subject of the research is, the results are obvious in this model. The aim is to observe and determine that object correctly. The main purpose is to observe without altering (Karasar, 1999). In Survey model, there are recording observations, identifying relationships between events and generalizations controlled immutable relations.

The universe of this research includes students who study in tourism and education faculties of Selcuk and Necmettin Erbakan Universities in 2014-2015 fall semester in Konya province. In this regard, 200 students from the Faculty of Tourism in Selcuk University and 250 students from Ahmet Kelesoglu Faculty of Education in Necmettin Erbakan University studying at both universities in the relevant period are selected by simple random sampling method and formed the research group. Demographic data questionnaire developed by researchers in the direction of sub-purposes and Education and "M-Learning Attitude Scale" developed by Celik (2013) is applied to education and tourism faculty students to collect data. Questions of the scale are developed as 5-item Likert type. The data obtained from the students has been evaluated through entering the SPSS 19.0 software package.

In order to determine whether there is a significant difference according to general evaluation of the situation for mobile technology, type of high school they graduated, their grade, whether they have their own computer or mobile device in their households, whether they have their own Internet in their households, t-test and analysis of 
covariance (ANCOVA) are performed for independent samples. The level of significance for all statistical analyses performed in this study has been accepted as .05.

Mobile learning applications are changing with technological developments which provide accessing knowledge regardless of time and space. Especially parallel to the development of Internet, processing capability is improved; although hardware is shrunk on technological devices. Today, mobile technologies not only are getting cheaper and improve interaction possibility, but also can provide distance learning opportunities for individuals (Oran \& Karadeniz, 2007). Therefore, it can be stated that mobile technologies are widely used in formal or informal training for educational purposes and it is likely to make more space in the future (Corlett, et al., 2005; Sharples, Taylor, \& Vavoula, 2005). From this point, university students' attitudes towards mobile learning are examined by considering and using the students from two different faculties (Faculty of Tourism and Faculty of Education) as control variable. The following results are obtained through scale developed by Celik (2013) from a total of 450 students.

Results: Faculty of Education and Faculty of Tourism students show differences in attitudes towards mobile learning. Faculty of Education students have more positive attitudes than Faculty of Tourism students. Usluel and Mazman (2010) stated perceived benefits, facilitating factors, social impact as key factors in technology acceptance, they asserted perceived benefits as the most important factor. From this perspective, attitudes may have been influenced by perceived benefits, facilitating factors, social impacts in both faculties. Lau and Woods (2008) stated that offered facilities and environment have impact. In this respect, the fact that faculty of education instructors have more mobile technology-oriented educational approach in social manner may also be the reason for this result. On the other hand, controlling faculty variable, the following result has been reached; there is no difference among attitudes for mobile learning in terms of gender, grades, graduated high school type and whether the Internet is available in households.

Discussion and Conclusions: Considering the results obtained in the research, it can be suggested that the research can be re-designed to include different faculties. The fact that there is no difference in terms of the grade variable for attitudes towards mobile learning may be resulted from not representing $1^{\text {st }}$ and $4^{\text {th }}$ grade students from both faculties. From this point, the research can be re-designed with a different sample. Adding qualitative dimension of mobile learning into research, the differences in students' attitudes can be investigated. 


\section{Kaynakça}

Akbıyık, A., \& Kantaroğlu, T. (2017). İşletme fakültesi ve eğitim fakültesi öğrencilerinin mobil öğrenmeye yönelik tutumlarının karşılaştırılması. Journal of Business Science (JOBS), 5(2), 25-50.

Bannan, B., Cook, J., \& Pachler, N. (2016). Reconceptualizing design research in the age of mobile learning. Interactive Learning Environments, 24(5), 938-953.

Baylari, A., \& Montazer, G. A. (2009). Design a personalized e-learning system based on item response theory and artificial neural network approach. Expert Systems with Applications, 36(4), 8013-8021.

Chang, C., Chen,T., \& Hsu, W. (2011). The study on integrating webquest with mobile learning for environmental education. Computers \& Education, 57, 1228-1239.

Cochrane, T. (2010). Mobile web 2.0: Bridging learning contexts. In S. Caballé, F. Xhafa, T. Daradoumis, \& A. A. Juan, Architectures for distributed and complex mlearning systems: Applying intelligent technologies (ss. 123-151). UAS: Information Science Reference.

Corlett, D., Sharples, M., Bull, S., \& Chan, T. (2005). Evaluation of a mobile learning organiser for university students. Journal of Computer Assisted Learning, 21, 162170 .

Çakır, H. (2011). Mobil öğrenmeye ilişkin bir yazılım geliştirme ve değerlendirme. Çukurova Üniversitesi Eğitim Fakültesi Dergisi, 2(40), 1-9.

Çelik, U. A. (2013). M-öğrenme tutum ölçeği: geçerlik ve güvenirlik analizleri. Journal of Research in Education and Teaching, 2(4), 172-185.

Davis, F.D., Bagozzi, R., \& Warshaw, P. (1989). User acceptance of computer technology: A comparison of two theoretical models. Management Science, 35(8), 982-1003.

Gay, G., Stefanone, M., Grace-Martin, M., \& Hembrooke, H. (2001) The effects of wireless computing in collaborative learning environments. International Journal of Human- Computer Interaction, 13(2), 257-276.

Harmandar, M., \& Samanc1, O. (2000). Eğitim fakültesi kimya eğitimi bölümü öğrencilerinin bilgisayara yönelik tutumları. IV. Ulusal Fen Bilimleri Kongresi Kongre Kitabı (ss.686-688). Ankara: Hacettepe Üniversitesi Eğitim Fakültesi.

Horzum, B., (2003). Öğretim elemanlarının internet destekli ĕgitime yönelik düşünceleri (Sakarya Üniversitesi Örneği) (Yayımlanmamış Yüksek Lisans Tezi). Sakarya.

Jones, S. (2002, 2008). The Internet goes to college: How students are living in the future with today's technology. Diane Publishing.

Jones, S. Johnson-Yale, C. Millermaier, S., \& Seoane Pérez, (2009). Everyday life, online: U.S. college students' use of the Internet. First Monday, 14(10), 9-11.

Karasar, N. (1999). Bilimsel araştırma yöntemi. Ankara: Nobel Yayınları.

Keleş, H. N., Özkan, T. K., Doğaner, M., \& Altunoğlu, A. E. (2015). Önlisans öğrencilerinin girişimcilik düzeylerini belirlemeye yönelik bir araştırma. Uluslararası İktisadi ve İdari Incelemeler Dergisi, (9), 45-59. 
Keskin, N., \& Ertuğrul, İ. (2010). Buldan MYO büro yönetimi öğrencilerinin bilgisayar kullanımına yönelik tutumlarının belirlenmesine ilişkin alan çalışması. Uluslararası İktisadi ve İdari Incelemeler Dergisi, 3(59), 1-20.

Kıc1, D. (2010). Üniversite öğrencilerinin mobil öğrenmenin üniversite eğitimindeki etkisi konusundaki beklentileri üzerine bir araştırma. International Conference On New Trends in Education and Their Implications, Antalya, Turkey.

Kinash, S., Brand, J., Mathew, T., \& Kordyban, R. (2011). Uncoupling mobility and learning: When one does not guarantee the other. In R. Kwan, C. McNaught, P. Tsang, F. L. Wang, K. C. Li (Eds.), Enhancing learning through technology. education unplugged: Mobile technologies and Web 2.0 (pp. 342-350). Springer Berlin Heidelberg.

Korkmaz, Ö. (2015). New trends on mobile learning in the light of recent studies. Participatory Educational Research, 1(2), 1-10.

Korucu, A. T., \& Alkan, A. (2013). Opinions of computer teacher nominees towards mobile learning. 7th International Computer and Instructional Technologies Symposium, June 6th - 8th 2012, Ataturk University, Erzurum, Turkey.

Köse, S., \& Gezer, K. (2006). Buldan (Denizli) ilçesi lise ögrencilerinin bilgisayara yönelik tutumları. Buldan Sempozyumunda sunulmuş sözlü bildiri. Pamukkale Üniversitesi, T.C. Buldan Kaymakamlığı, Buldan Belediyesi, Denizli.

Kukulska-Hulme, A. (2013). Mobile learners: Who are they and who will they become? Berge, Z. L., \& Muilenburg, L. Y. (Eds.), Handbook of mobile learning (145-155). New York, USA: Routledge Taylor and Francis Group.

Lau, S. H., \& Woods, P. C. (2008). An investigation of user perceptions and attitudes towards learning objects. British Journal of Educational Technology, 39(4), 685699.

Oran, M. K., \& Karadeniz, Ş. (2007). Internet tabanll uzaktan ĕgitimde mobil ögrenmenin rolü. http://ab.org.tr/ab07/bildiri/66.pdf adresinden 18.12.2017 tarihinde erişilmiştir.

Ozan, Ö. (2013). Bağlantıcı (Connectivist) mobil öğrenme ortamlarında yönlendirici destek (scaffolding) (Yayımlanmamış doktora tezi). Eskişehir: Anadolu Üniversitesi.

Seppala, P., \& Alamaki, H. (2003) Mobile Learning in teacher training, Journal of Computer Assisted Learning, 19, 330-335.

Quinn, C. N. (2000). mLearning: Mobile, wireless, in-your-pocket learning. Retrieved from http://www.linezine.com/2.1/features/cqmmwiyp.htm

Reychav, I., \& Wu, D. (2014). Exploring mobile tablet training for road safety: A uses and gratifications perspective. Computers \& Education, 1(71) 43-55.

Şahin, M., \& Kışla, T. (2013). Kişiselleştirilebilir öğrenme ortamları: Literatür incelenmesi. Ĕğitim ve Öğretim Araştırmaları Dergisi, 2(1), 81-91.

Saran, M., Seferoğlu, G., \& Çağıltay, K. (2009). Mobile assisted language learning: English pronunciation at learners' fingertips. Eurasian Journal of Educational Research, 34, 97-114. 
Sharples, M., Taylor, J., \& Vavoula, G. (2005). Towards a theory of mobile learning. In Proceedings of mLearn, 1(1), 1-9.

Usluel, Y. K., \&, Mazman, S. G. (2010). Eğitimde yeniliklerin yayılımı, kabulü ve benimsenmesi sürecinde yer alan öğeler: Bir içerik analizi çalışması. Çukurova Üniversitesi Eğitim Fakültesi Dergisi, 3(39), 60-74.

Zhang, Y. (2007). Development and validation of an internet use attitude scale. Computers \& Education, 49(2), 243-253. 